\title{
Children's discomfort in assessments using different methods for approximal caries detection
}

Tatiane Fernandes Novaes ${ }^{(a)}$ Ronilza Matos ${ }^{(a)}$

Daniela Prócida Raggio(a) Mariana Minatel Braga ${ }^{(a)}$ Fausto Medeiros Mendes(a)

(a) Department of Pediatric Dentistry, School of Dentistry, University of São Paulo, São Paulo, SP, Brazil.
Declaration of Interests: The authors certify that they have no commercial or associative interest that represents a conflict of interest in connection with the manuscript.

\section{Corresponding author:}

Tatiane Fernandes Novaes

E-mail: tatifn@usp.br

Received for publication on Aug 29, 2011 Accepted for publication on Dec 09, 2011

\begin{abstract}
Because discomfort caused by different approximal caries detection methods can influence their performance, the assessment of this discomfort is important. Thus, this study aimed to evaluate the discomfort reported by children after the use of different diagnostic methods to detect approximal caries lesions in primary teeth: visual inspection, bitewing radiography, laser fluorescence (DIAGNOdent pen - LFpen) and temporary separation with orthodontic rubbers. Seventy-six children aged 4 to 12 years were examined using these methods. Their discomfort was assessed using the Wong-Baker scale and compared among the methods. Visual inspection caused less discomfort than did other methods. Radiography and the LFpen presented similar levels of discomfort. Older children reported higher discomfort using temporary separation, whereas younger children reported less discomfort with the LFpen. In conclusion, radiographic, temporary separation and LFpen methods provoke higher discomfort than visual inspection.
\end{abstract}

Descriptors: Sensation; Diagnosis; Dental Caries.

\section{Introduction}

The detection of approximal caries lesions is difficult because the contact points hamper the direct visual inspection of pertinent tooth surfaces. Conventional methods have been used for this purpose. Visual inspection is the most commonly used method, although it is associated with low sensitivity and reliability in detecting approximal caries lesions. ${ }^{1}$ Although the radiographic method can increase the sensitivity of visual inspection, it underestimates the actual depth of the lesion and is unable to show the presence of cavitation. ${ }^{2}$ Temporary separation with orthodontic rubbers is a good alternative to visually detect the presence of cavitations, although this method requires two appointments. ${ }^{3} \mathrm{Re}-$ cently, a pen-type laser fluorescence device (LFpen) was introduced for the detection of approximal caries lesions. ${ }^{4}$

Visual inspection is a relatively easy and fast technique, although assessments using a scoring system, such as the International Caries Detection and Assessment System (ICDAS), could increase the time spent in clinical examinations. ${ }^{5}$ The radiographic method, by contrast, may be difficult to perform in children because the size of the film or its holder (e.g, the one used to take bitewing radiographs) may cause some intraoral discomfort. ${ }^{6}$ This discomfort has also been observed in adults. ${ }^{7,8}$ Pain 
and discomfort have also been reported with orthodontic rubbers for temporary separation. ${ }^{9}$ To assess approximal surfaces with the LFpen, a sapphire tip that is $0.4 \mathrm{~mm}$ in thickness and $1.1 \mathrm{~mm}$ in width must be introduced under the contact point. This procedure could also provoke some discomfort.

The performance of these different methods in the detection of approximal caries lesions has been previously investigated. ${ }^{4,10,11}$ Furthermore, the discomfort caused by these methods has been reported to influence their performance, ${ }^{12}$ although no previous study has assessed the discomfort caused by each of these methods in pediatric patients. Therefore, we investigated the discomfort reported by children whose primary teeth were examined for approximal caries lesions using visual inspection, radiography, the LFpen and temporary separation with orthodontic rubbers. We also assessed possible associations between certain variables and the level of discomfort.

\section{Methodology}

This study was approved by the local Committee for Ethics in Research (Protocol 115/07). We identified the enrolment forms of 80 children who sought dental treatment in our dental school and invited them to participate in the study. Four children refused to participate (positive response rate of $95 \%$ ). Thus, 76 children (32 males and 44 females) aged 4 to 12 years (mean $7.3 \pm 1.6$ years old) and living in São Paulo, Brazil (with $0.7 \mathrm{mg} / \mathrm{L} \mathrm{F}^{-}$in water supply) took part in the study. Nine children $(11.8 \%)$ presented with primary dentition and $67(88.2 \%)$ with mixed dentition.

Primary molars without restorations or frank cavitations and their adjacent teeth were selected in these children (592 approximal surfaces). Then, two graduate students with experience in caries diagnosis (TFN and RM) assessed the surfaces using different methods of approximal caries detection:

- visual inspection,

- radiography and

- the LFpen (DIAGNOdent pen, Kavo, Biberach, Germany).

The different diagnostic methods were applied in random order. The training of the examiners and the calibration processes were previously described. ${ }^{11}$

All examinations were carried out in a dental chair with operating light illumination and a 3 -in1 syringe. After the cleaning procedures, visual inspection was first performed using a plane buccal mirror and a WHO periodontal probe, using ICDAS criteria. ${ }^{5}$

For the radiographic examinations, bitewing radiographs that comprised the maxillary and mandibular primary molars were taken from each side (two radiographs for each child). The X-ray machine (Spectro 70 X, Dabi Atlante, Ribeirão Preto, Brazil) was set to $70 \mathrm{kV}$ and $8 \mathrm{~mA}$, and the exposure time was 0.3 s. Kodak Insight radiographic films $(22 \times 35 \mathrm{~mm}$, Eastman Kodak, Rochester, USA) were used with a focus-to-film distance of $40 \mathrm{~cm}$. The films were developed manually using standard processing times. Radiographs were initially attempted with the use of plastic bitewing holders (Jon Han-Shin PF 682, Jon Ind., São Paulo, Brazil). If the child did not tolerate the holder, a bitewing was made using adhesive tape instead $(\mathrm{n}=13)$.

For the LFpen method, calibration procedures were first performed against a reference object and on a sound smooth surface of each examined tooth. Next, the tip for the approximal surfaces (tip 1) was introduced underneath the contact area, initially from the buccal side and then from the oral side, according to the manufacturer's instructions. After all assessments, the children were submitted to temporary separation of each surface using orthodontic rubber rings (Morelli, Sorocaba, Brazil), which were placed around the contact points for 7 days.

For the assessment of discomfort, we used the Wong-Baker FACES pain rating scale, ${ }^{13}$ which is an ordinal six-point scale ranging from 0 to 5 . A score of 0 shows a smiling face, indicating no discomfort, whereas a score of 5 shows a crying and sad face, indicating great discomfort. This method was previously validated for the assessment of pain and discomfort in children. ${ }^{13,14}$

All of the children were subjected to all of the diagnostic methods tested by both examiners at the same appointment. Immediately after the assessment, one examiner (TFN) asked the child to indicate the 
face that best represented his/her feeling regarding the method. For the method of temporary separation with orthodontic rubber, discomfort was assessed immediately after placing the orthodontic rubber in one approximal space. Then, the discomfort of this method was evaluated again at the recall visit, seven days later. For the temporary separation method, discomfort was evaluated in only 50 children. Evaluations were not performed in 26 children because of the lack of time at the end of the appointments, patient absence at the recall visit or loss of the rubber in the days following the initial placement.

After the discomfort scores were recorded for each method, we employed the Friedman test to compare the degrees of discomfort among the methods. Poisson regression analysis was used to evaluate the association between gender, age and type of dentition with the discomfort degree. For the radiographic method, another explanatory variable was the technique used for taking the bitewing radiographs (whether using adhesive tape or plastic film holders). We considered the scores attributed using the Wong-Baker scale as our outcomes. Rate ratios and $95 \%$ confidence intervals were then calculated. For all statistical analyses, the level of significance was set at $\mathrm{p}<0.05$.

\section{Results}

Regarding agreement between examiners, all of the methods demonstrated both high inter- and intra-examiner reproducibility values, with Kappa values ranging from 0.7 to 1.0 .

Considering all samples, the radiographic $($ mean $\pm \mathrm{SD}=0.72 \pm 1.13 ;$ median $=0 ;$ range $=0-5)$ and LFpen methods (mean $\pm \mathrm{SD}=0.76 \pm 1.02$; median $=0.5$; range $=0-5$ ) provoked similar levels of discomfort. Both methods provoked higher levels of discomfort than did visual inspection ( mean $\pm \mathrm{SD}=0.42 \pm 0.72$; median $=0$; range $=0-3$ ). However, the degree of discomfort was not significant; the mean of the scores was lower than 1.0. Figure 1 shows the distribution of the scores among the different methods.

In children submitted to temporary tooth separation $(\mathrm{n}=50)$, this method caused similar levels of discomfort than did the radiographic and LFpen methods immediately after placement of the orthodontic rubber (mean $\pm \mathrm{SD}=0.84 \pm 1.02$, median $=1$; range $=0-5)$. However, this method also caused significantly higher levels than visual inspection. In contrast, at the time of the recall visit, the children reported lower levels of discomfort provoked by the orthodontic rubber $($ mean $\pm \mathrm{SD}=0.64 \pm 0.96$, median $=0$; range $=0-4$ ). This method did not display statistically significant differences from the other methods (Figure 1).

Older children and those with mixed dentition reported significantly less discomfort with the LF-

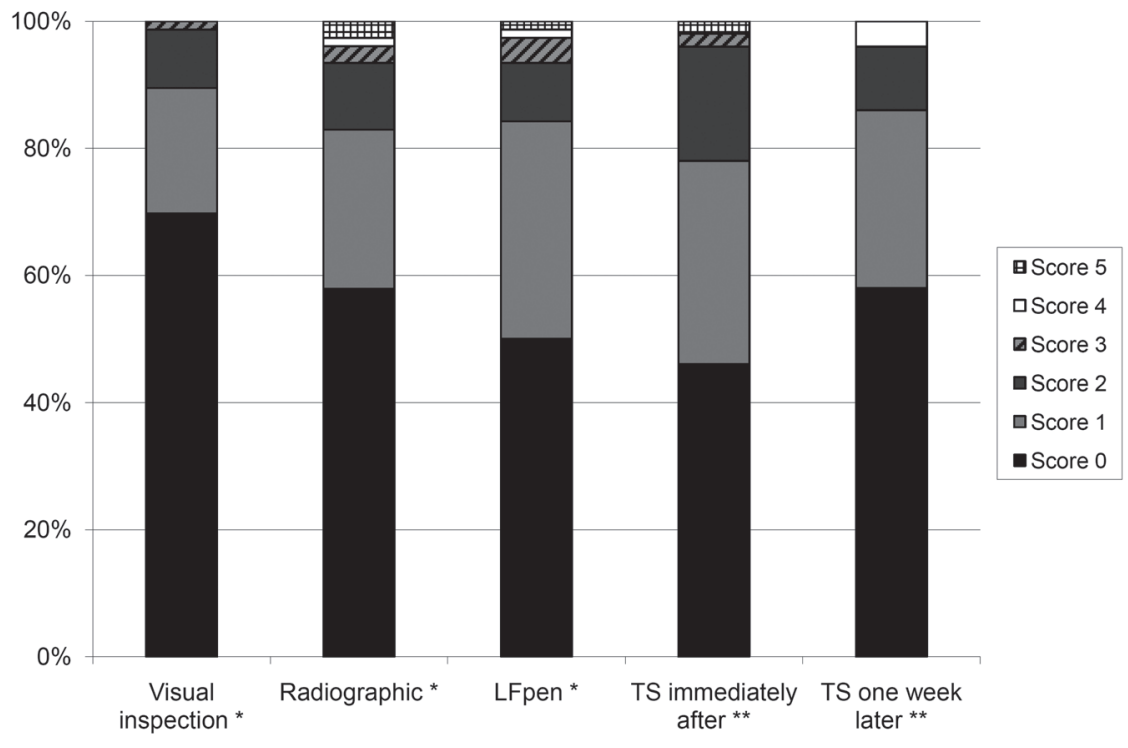

Figure 1 - Distribution of discomfort scores reported by children subjected to different methods for approximal caries detection (LFpen $=$ Laser fluorescence method; $\mathrm{TS}=$ temporary separation with orthodontic rubbers; ${ }^{*} \mathrm{n}=76$; $\left.{ }^{* *} n_{n}=50\right)$. 
Table 1 - Associations between gender, age and type of dentition and the degree of discomfort reported by children who were subjected to different methods of approximal caries detection.

\begin{tabular}{|c|c|c|c|c|c|}
\hline \multirow{2}{*}{ Explanatory variables } & Visual inspection** & Radiographic** & LFpen** & TS (immediately after) ${ }^{* * *}$ & TS (one week after) ${ }^{* * *}$ \\
\hline & \multicolumn{5}{|c|}{ Rate ratio ( $95 \%$ confidence interval) } \\
\hline $\begin{array}{c}\text { Gender } \\
\text { (ref.: male) }\end{array}$ & $\begin{array}{c}1.21 \\
0.54 \text { to } 2.70\end{array}$ & $\begin{array}{c}1.94 \\
0.92 \text { to } 4.07\end{array}$ & $\begin{array}{c}0.96 \\
0.53 \text { to } 0.94\end{array}$ & $\begin{array}{c}0.98 \\
0.47 \text { to } 2.03\end{array}$ & $\begin{array}{c}2.00 \\
0.83 \text { to } 4.83\end{array}$ \\
\hline $\begin{array}{c}\text { Age } \\
\text { (cont. var.) }\end{array}$ & $\begin{array}{c}0.82 \\
0.64 \text { to } 1.06\end{array}$ & $\begin{array}{c}0.93 \\
0.74 \text { to } 1.16\end{array}$ & $\begin{array}{c}0.73^{*} \\
0.57 \text { to } 0.94\end{array}$ & $\begin{array}{c}1.19^{*} \\
1.04 \text { to } 1.36\end{array}$ & $\begin{array}{c}1.00 \\
0.82 \text { to } 1.21\end{array}$ \\
\hline $\begin{array}{c}\text { Dentition } \\
\text { (ref.: primary) }\end{array}$ & $\begin{array}{c}0.48 \\
0.22 \text { to } 1.07\end{array}$ & $\begin{array}{c}1.10 \\
0.23 \text { to } 5.33\end{array}$ & $\begin{array}{c}0.32^{*} \\
0.17 \text { to } 0.62\end{array}$ & - & $\begin{array}{c}1.07 \\
0.30 \text { to } 3.79\end{array}$ \\
\hline $\begin{array}{l}\text { Radiographic method } \\
\text { (ref.: adhesive tape) }\end{array}$ & - & $\begin{array}{c}0.93 \\
0.38 \text { to } 2.25\end{array}$ & - & - & - \\
\hline
\end{tabular}

*Statistically significant at $0.05 ;{ }^{* *} \mathrm{n}=76 ;{ }^{* * *} \mathrm{n}=50 ; \mathrm{LFpen}=$ Laser fluorescence method; TS $=$ Temporary separation with orthodontic rubber.

pen than did younger children and children with primary dentition (Table 1). However, regarding the discomfort caused by temporary separation immediately after the placement of the orthodontic rubber, significantly higher levels of discomfort were reported by older children than by younger children (Table 1). Age and the type of dentition did not present significant associations with the other methods. Gender also failed to show significant associations with any method. For the radiographic method, there were no statistically significant differences in reported discomfort between bitewing radiographs involving a film-holder and with bitewings constructed with adhesive tape (Table 1).

\section{Discussion}

Because most studies assessing caries detection methods have focused mainly on the diagnostic performance, ${ }^{1}$ there is a lack of research investigating the best health outcomes for patients..$^{15}$ Discomfort provoked by diagnostic methods may cause problems because discomfort can influence the quality of the technique and increase the probability of diagnostic errors. ${ }^{6-8}$ Furthermore, if the diagnostic method provokes discomfort at the initial appointment, this could lead to increased dental fear and anxiety in subsequent appointments. Previous negative experiences have been identified as a causative factor for behavioral problems in children in dental settings. ${ }^{16}$ Therefore, we aimed to investigate the discomfort provoked by different methods of approximal caries detection in primary teeth and to identify associa- tions with various factors.

The evaluation of pain and discomfort in children is a difficult task because of the subjective nature of the methods. The behaviors and expressions of the pediatric patient may not accurately reflect the reporting of symptoms because preschool children have limited verbal fluency with which to communicate their feelings. This was a limitation of our study, although the use of scales has been widely reported with proven validity of results. ${ }^{6}$ In our sample, the subjects did not show any difficulty in identifying the faces that represented their feelings.

We used the Wong-Baker FACES pain rating scale because it is an instrument that has been validated in patients aged 3 to 18 years. Furthermore, it is a reliable tool that has been translated into several languages and is extensively employed to evaluate pain and discomfort for a variety of clinical procedures. ${ }^{13,17,18}$ Previous studies have compared different methods of pain and discomfort assessment for children. Although these methods presented similar validity and reliability scores, the acceptance by children was higher with the Wong-Baker scale. ${ }^{13,14}$

In our study, visual inspection was the method that caused the lowest levels of discomfort. Other authors have confirmed that visual inspection is an easy and fast method. ${ }^{1,19,20}$ Examinations performed using ICDAS can take longer than those using other methods, such as the WHO criteria. ${ }^{21}$ However, the low degree of discomfort reported by children receiving visual inspection corroborates that ICDAS may be feasible for use in the pediatric population. 
The two other methods, in contrast, provoked higher levels of discomfort. With the radiographic method, both the use of a holder or film alone has been reported to cause some discomfort in children. ${ }^{6,22}$ Our study corroborates these findings. Discomfort due to radiographic digital receptors has also been reported by adults. ${ }^{7,8}$ Attempts to adjust the size and format of bitewing positioning devices for young children should be considered to reduce this discomfort. ${ }^{6,22}$

The LFpen method also provoked some discomfort in children during the examinations of approximal surfaces. Only one previous in vivo study has been published assessing the LFpen on approximal surfaces, although this study did not address patient complaints about the method. ${ }^{11}$ Thus, the present study is the first to investigate discomfort provoked by the LFpen method. In another study, we observed that discomfort can influence the performance of the LFpen. ${ }^{12}$ The thickness of the tip and the need to introduce the tip into the contact area may be among the factors responsible for the discomfort. Thinner tips could cause less discomfort, which the manufacturer should consider.

Regarding temporary separation, orthodontic rubbers in permanent teeth may provoke pain in children both immediately and one day after the placement of the rubber. One week after the placement of the rubber, however, the pain and discomfort subsided. ${ }^{9}$ In primary teeth, we observed similar results. In addition, and in accord with the results from other studies, the use of separators for seven days was adopted without substantial patient inconvenience or loss of the orthodontic rubbers. ${ }^{23,24}$

The discomfort caused by orthodontic rubbers was similar to that of other methods such as radiography and the LFpen. Thus, discomfort is not a significant deficiency associated with this method. However, the main disadvantage is that two appointments are needed to make a diagnosis. Temporary separation was previously reported as a valuable and relatively non-traumatic adjunct diagnostic method..$^{25,26}$

With the LFpen, older children complained of less discomfort than did younger children. Children with mixed dentition also complained of less dis- comfort than did children with primary dentition. However, the type of dentition and age are collinear variables, and the association with age was stronger. This method is very lengthy and requires long appointment times, which may explain the aforementioned association. In our study, none of the children had previous exposure to the LFpen, a relatively new device on the market.

Regarding temporary separation, however, older children reported higher levels of discomfort. A possible explanation is that because teeth in mixed dentition are more firmly anchored to the alveolar bone, they are harder to move than are teeth in the primary dentition. ${ }^{27,28}$ This fact may explain the abovementioned association. In addition, some mobility associated with primary molars in the exfoliation process may have been caused by the action of the orthodontic rubber separator against the tight contact points in older children, resulting in higher degrees of discomfort. Other variables did not present statistically significant associations. The radiographic method performed with plastic film holders caused levels of discomfort similar to those caused by bitewing radiography performed with adhesive tape.

Radiography, the LFpen and temporary separation provoked similar degrees of discomfort, which were higher than that provoked by visual inspection. Nevertheless, the mean level of discomfort for all methods was relatively low (i.e., lower than 1 in a scale of 0 to 5). Thus, we could affirm that caries detection methods for approximal surfaces are usually painless. However, some children reported a discomfort score of 5. Moreover, discomfort can influence the performance of these methods in detecting approximal carious lesions. ${ }^{12}$ This influence is relevant because over- or under-diagnosis may induce undesirable errors in subsequent treatment. Therefore, dentists should try to minimize discomfort to manage the behavior of children during treatment.

The previous experience of children in dental clinical settings may have influenced their willingness to accept certain diagnostic methods that were evaluated. The use of the LFpen was unknown by all of the subjects who were part of our sample. However, previous exposure to radiographs and/or the 
use of rubber rings were not assessed, which may have been a limitation in our study. Other results, however, did not display a correlation between past experience and current behavior in children during the radiographic examination. ${ }^{6}$

\section{Conclusion}

Radiography, the LFpen and temporary separation provoke greater discomfort than does visual inspection, although the degree of discomfort was generally low. The age of the child is the factor that

\section{References}

1. Bader JD, Shugars DA, Bonito AJ. A systematic review of the performance of methods for identifying carious lesions. J Public Health Dent. 2002 Dec;62(4):201-13.

2. Wenzel A. Bitewing and digital bitewing radiography for detection of caries lesions. J Dent Res. 2004 Jul;83 Spec No $\mathrm{C}: \mathrm{C} 72-5$

3. de Araujo FB, de Araujo DR, dos Santos CK, de Souza MA. Diagnosis of approximal caries in primary teeth: radiographic versus clinical examination using tooth separation. Am J Dent. 1996 Apr;9(2):54-6.

4. Lussi A, Hack A, Hug I, Heckenberger H, Megert B, Stich H. Detection of approximal caries with a new laser fluorescence device. Caries Res. 2006 Feb;40(2):97-103.

5. Ismail AI, Sohn W, Tellez M, Amaya A, Sen A, Hasson H, et al. The International Caries Detection and Assessment System (ICDAS): an integrated system for measuring dental caries. Community Dent Oral Epidemiol. 2007 Jun;35(3):170-8.

6. Pierro VS, Barcelos R, de Souza IP, Raymundo RJ. Pediatric bitewing film holder: preschoolers' acceptance and radiographs' diagnostic quality. Pediatr Dent. 2008 JulAug;30(4):342-7.

7. Goncalves A, Wiezel VG, Goncalves M, Hebling J, Sannomiya EK. Patient comfort in periapical examination using digital receptors. Dentomaxillofac Radiol. 2009 Oct;38(7):484-8.区

8. Wenzel A, Frandsen E, Hintze H. Patient discomfort and cross-infection control in bitewing examination with a storage phosphor plate and a CCD-based sensor. J Dent. 1999 Mar;27(3):243-6.

9. Giannopoulou C, Dudic A, Kiliaridis S. Pain discomfort and crevicular fluid changes induced by orthodontic elastic separators in children. J Pain. 2006 May;7(5):367-76.

10. Braga MM, Morais CC, Nakama RC, Leamari VM, Siqueira WL, Mendes FM. In vitro performance of methods of approximal caries detection in primary molars. Oral Surg Oral Med Oral Pathol Oral Radiol Endod. 2009 Oct;108(4):e35-41.

11. Novaes TF, Matos R, Braga MM, Imparato JCP, Raggio DP, Mendes FM. Performance of pen-type laser fluorescence de- is most associated with the level of reported discomfort.

\section{Acknowledgements}

The study was supported by the Conselho $\mathrm{Na}$ cional de Desenvolvimento Científico e Tecnológico (CNPq - Process \#476372/2006-2, 302368/2008-6 and 565061/2008-9), Fundação de Amparo à Pesquisa do Estado de São Paulo (FAPESP - Process 2009/16082-0) and Pró-Reitoria de Pesquisa e de Pós-Graduação da USP.

vice and conventional methods in detecting approximal caries lesions in primary teeth - in vivo study. Caries Res. 2009 Mar;43(1):36-42.

12. Novaes TF, Matos R, Raggio DP, Imparato JC, Braga MM, Mendes FM. Influence of the Discomfort Reported by Children on the Performance of Approximal Caries Detection Methods. Caries Res. 2010 Nov;44(5):465-71.

13. Wong DL, Baker CM. Pain in children: comparison of assessment scales. Pediatr Nurs. 1988 Jan-Feb;14(1):9-17.

14. Luffy R, Grove SK. Examining the validity, reliability, and preference of three pediatric pain measurement tools in African-American children. Pediatr Nurs. 2003 JanFeb;29(1):54-9.

15. Baelum V, Heidmann J, Nyvad B. Dental caries paradigms in diagnosis and diagnostic research. Eur J Oral Sci. 2006 Aug;114(4):263-77.

16. Klingberg G, Broberg AG. Dental fear/anxiety and dental behaviour management problems in children and adolescents: a review of prevalence and concomitant psychological factors. Int J Paediatr Dent. 2007 Nov;17(6):391-406.

17. Rajasagaram U, Taylor DM, Braitberg G, Pearsell JP, Capp BA. Paediatric pain assessment: differences between triage nurse, child and parent. J Paediatr Child Health. 2009 Apr;45(4):199-203.

18. Talamo G, Liao J, Bayerl MG, Claxton DF, Zangari M. Oral administration of analgesia and anxiolysis for pain associated with bone marrow biopsy. Support Care Cancer. 2010 Mar;18(3):301-5.

19. Braga MM, Mendes FM, Martignon S, Ricketts DN, Ekstrand KR. In vitro comparison of Nyvad's system and ICDAS-II with Lesion Activity Assessment for evaluation of severity and activity of occlusal caries lesions in primary teeth. Caries Res. 2009 Oct;43(5):405-12.

20. Pitts NB. Current methods and criteria for caries diagnosis in Europe. J Dent Educ. 1993 Jun;57(6):409-14.

21. Braga MM, Oliveira LB, Bonini GA, Bonecker M, Mendes FM. Feasibility of the International Caries Detection and As- 
sessment System (ICDAS-II) in epidemiological surveys and comparability with standard World Health Organization criteria. Caries Res. 2009 Jul;43(4):245-9.

22. Pitts NB, Hamood SS, Longbottom C, Rimmer PA. The use of bitewing positioning devices in children's dentistry. Dentomaxillofac Radiol. 1991 Aug;20(3):121-6.

23. Pitts NB, Longbottom C. Temporary tooth separation with special reference to the diagnosis and preventive management of equivocal approximal carious lesions. Quintessence Int. 1987 Aug;18(8):563-73.

24. Pitts NB, Kidd EA. The prescription and timing of bitewing radiography in the diagnosis and management of dental caries: contemporary recommendations. Br Dent J. 1992 Mar;172(6):225-7.

25. Rimmer PA, Pitts NB. Temporary elective tooth separation as a diagnostic aid in general dental practice. Br Dent J. 1990 Aug;169(3-4):87-92.
26. Mialhe FL, Pereira AC, Pardi V, de Castro Meneghim M. Comparison of three methods for detection of carious lesions in proximal surfaces versus direct visual examination after tooth separation. J Clin Pediatr Dent. 2003 Jun;28(1):59-62.

27. Allison PJ, Schwartz S. Interproximal contact points and proximal caries in posterior primary teeth. Pediatr Dent. 2003 Jul-Aug;25(4):334-40.

28. Hintze H, Wenzel A, Danielsen B, Nyvad B. Reliability of visual examination, fibre-optic transillumination, and bite-wing radiography, and reproducibility of direct visual examination following tooth separation for the identification of cavitated carious lesions in contacting approximal surfaces. Caries Res. 1998 May-Jun;32(3):204-9. 